\title{
Acoustic Description of Bird Broiler Vocalisations in a Real-Life Intensive Farm and Its Impact on Animal Welfare: A Comparative Analysis of Recordings ${ }^{+}$
}

\author{
Gerardo José Ginovart-Panisello ${ }^{1,2, * \mathbb{C}}$, Rosa Ma Alsina-Pagès ${ }^{1}\left(\mathbb{C}\right.$ and Tesa Panisello Monjo ${ }^{2}$ \\ 1 Grup de Recerca en Tecnologies Mèdia (GTM), La Salle-Universitat Ramon Llull, C/Quatre Camins, 30, \\ 08022 Barcelona, Spain; gerardojose.ginovart,rosamaria.alsina@salle.url.edu \\ 2 Cealvet SLu, C/Sant Josep de la Montanya 50-B, 43500 Tortosa, Spain; tesapm@cealvet.com \\ * Correspondence: gerardojose.ginovart@salle.url.edu; Tel.: +34-93-2902455 \\ + Presented at the 7th International Electronic Conference on Sensors and Applications, 15-30 November 2020; \\ Available online: https:/ / ecsa-7.sciforum.net/
}

Published: 15 November 2020

check for updates

\begin{abstract}
The poultry meat industry is one of the most efficient biological systems to transform cereal protein into high quality protein for human consumption at a low cost. However, to supply the increasing demand of white meat intensive production is required and also it generates stress to animals, which can be major sources of welfare problems. In this study, a comparative acoustic analysis of two entire production cycle of an intensive broiler Ross 308 poultry farm in the Mediterranean area has been performed. The following step to consolidate the analysis is to stablish a clear comparison among the performance of the indicators $\left(L_{e q}, L_{e q}\right.$ variation, Peak Frequency $(\mathrm{PF})$ and PF variation) in the conditions of two different recording campaigns corresponding to summer and winter entire production cycles. The acoustic maps of PF, $L_{e q}$ and the related variations should be validated in an inter-campaign comparison, which may also arise the possibility of changes due to the season of the year.
\end{abstract}

Keywords: bird well-fare; peak frequency; equivalent level vocalisation; PLF

\section{Introduction}

The demand for poultry meat due for the low price and the nutritional properties projects a continuous expansion of the poultry market [1,2]. In recent years, genetic selection has been performed during years to increase the growth rate in the shortest possible time [3] in the context of poultry meat industry [4]. As well as, the welfare of animals has become an important fact for society in many countries of the world. According to the world animal protection [5] organisation the farm animals raised humanely are healthier. This fact, together with the automatising of most of the animal monitoring processes, can support the farmer in the care of the animals.

Following this idea, bioacoustics studies the biological significance and the characteristics of sounds emitted by living organisms [6], and can be a relevant issue to complement the traditional measurements of the farm. Threat signals [7], information about feeding [8] or sexual selection [9] are only some examples of the possible applications of this field. More particularly, bird area is one of the few groups of animals known to exhibit vocal learning for communication [10]. The birds' vocalization is a useful tool to improve the state of health and well-being. The sound produced by the animals is a biological signal that can be easily measured from distance and therefore will not cause any additional stress to them [11].

In this study a comparative analysis in acoustic terms of $L_{e q}, \Delta L_{e q}$, Peak Frequency (PF), $\triangle P F$ has been performed between two production cycle over winter and summer season in a Spanish farm. 
Results show the variations and stability of the acoustic descriptions over seasons where different animal lots are grown in opposite climates.

This paper is structured as follows. The recording campaigns design required to obtain the data is detailed in Section 2. The results of the comparison of the two campaigns are available in Section 3. Finally, the discussion of the key aspects of the comparative is found in Section 4.

\section{Recording Campaigns Design}

A broiler Ross 308 takes approximately 44 days to complete the production cycle [12]. In a natural year a farm can hold in average six different birds' lots. The recording campaigns of this study are held in Spain over 2020. The climate between summer and winter is the opposite and it is an ideal scenario for a comparative study. In summer the farm is exposed to an external temperature of $31{ }^{\circ} \mathrm{C}-14{ }^{\circ} \mathrm{C}$ and a humidity of $4 \%-55 \%$ meanwhile in winter is $13{ }^{\circ} \mathrm{C}-1{ }^{\circ} \mathrm{C}$ and a humidity of $0 \%$ (Data obtained in average climate searcher https:/ / es.weatherspark.com (accessed on 15 September 2020)).

\subsection{Time Schedule Required}

The two campaigns of acoustic data recording have been performed in the same house farm, maintaining the deployed equipment and the genetic of birds. First campaign (C1) was scheduled during January and February 2020. Second campaign (C2) was scheduled during July and August 2020. Both cycles had a standard performance in terms of conversion index.

\subsection{Farm and Equipment Description}

The acoustic analysis has been performed in a Mediterranean farm of the BonArea Agrupa corporation (BonArea Agrupa www.bonarea-agrupa.com (accessed on 15 September 2020)) of approximately 42,000 commercial chicken farming of Ross 308 [13]. The characteristics of this farm provide a suitable environment for this study, because the automation reduces the human factor in farm management, and therefore, the man-made noise. So, the acoustic environment of the farm allows us to obtain suitable animals vocalization metrics.

A professional handheld recorder (Zoom H5) [14] was used, connected to a directional microphone Behringer ultravoice XM1800S with a frequency response of $80-15 \mathrm{kHz}$ and a sensibility of $2.5 \mathrm{mV} / \mathrm{Pa}$ [15]. The sounds emitted by birds were recorded with one microphone, deployed at one meter high from the ground and at the center to the house. The system captured data $24 / 7$ throughout the entire cycle with some technical resets, due to performing restrictions of the recorders.

More details about the Farm and Equipment description can be found in the former article of the same authors [16], which was devoted to the analysis of the first recorded cycle.

\section{Results}

In this section we present the results of the first comparison between the two recording campaigns, in which we map both the $L_{e q}$ value each $30 \mathrm{~min}$ for both campaigns, and also the $L_{e q}$ variation. We also map the PF every $30 \mathrm{~min}$ for both campaigns, and its variation values.

Figures 1 and 2 shows a map of $L_{\text {eq }}$. Values below $40 \mathrm{~dB}$ correspond to moments without or with less birds in the farm. In general, $L_{e q}$ do not present variations in age related. Even so, winter campaign has an increase of value measured during daylight, meanwhile in summer this pattern is not found but more peaks of high values are found.

Figures 3 and 4 show a map of the metric $\Delta L_{e q}$. In both campaigns, the highest variations corresponds to the arrival of the birds. Also, the value is reduced the first 20 days. From then on, an increase of level variation can be observed during daylight.

Figures 5 and 6 show a map of PF where the highest and long-lasting frequency are observed the first days of bird's life. The summer campaign presents more sporadic peak values than the winter one. 
Figures 7 and 8 show a map of the $\triangle P F$. Highest variations are observed in both campaigns at the end of the production cycle (last 5 days) and an increase of PF variation according with the birds' age is also a pattern found in both campaigns.

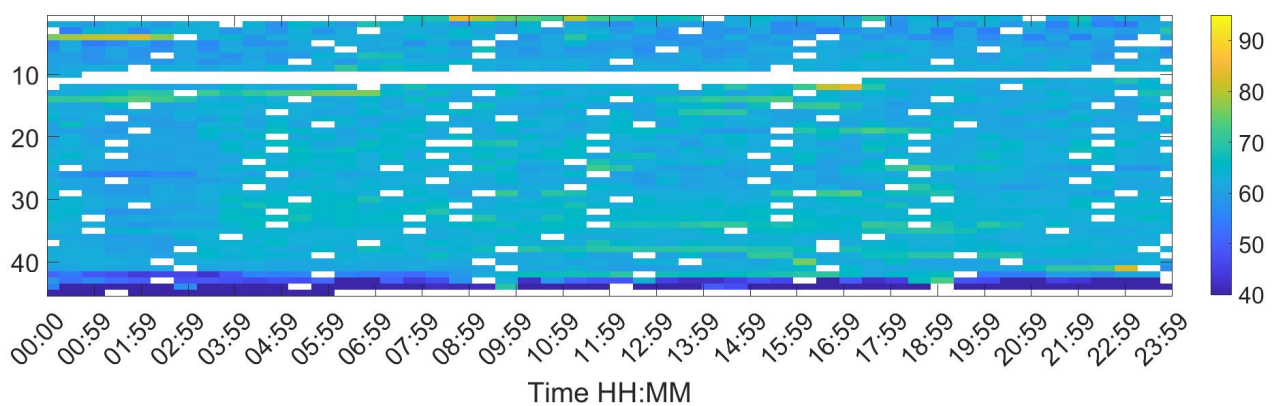

Figure 1. Map of the $L_{e q}$ values for each day of the first campaign (C1). One value each $30 \mathrm{~min}$.

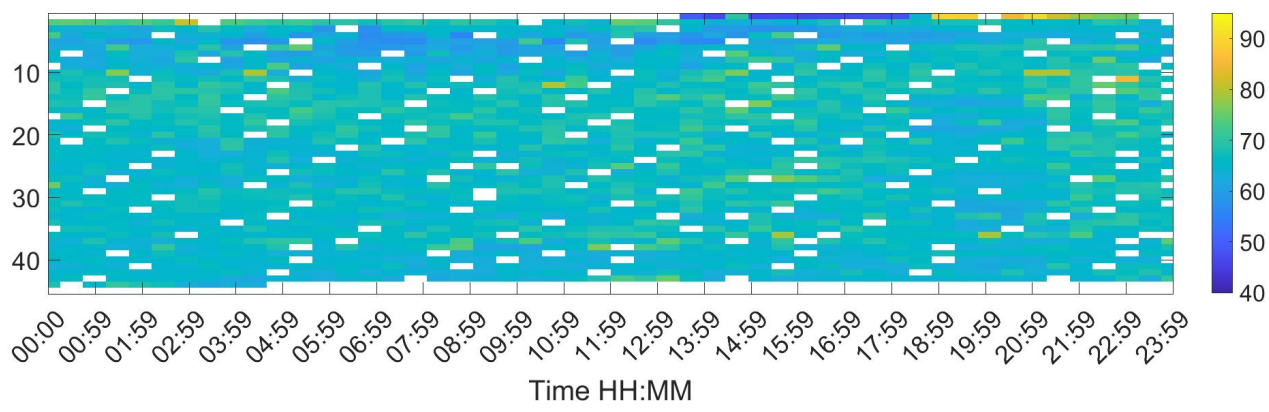

Figure 2. Map of the $L_{e q}$ values for each day of the second campaign (C2). One value each $30 \mathrm{~min}$.

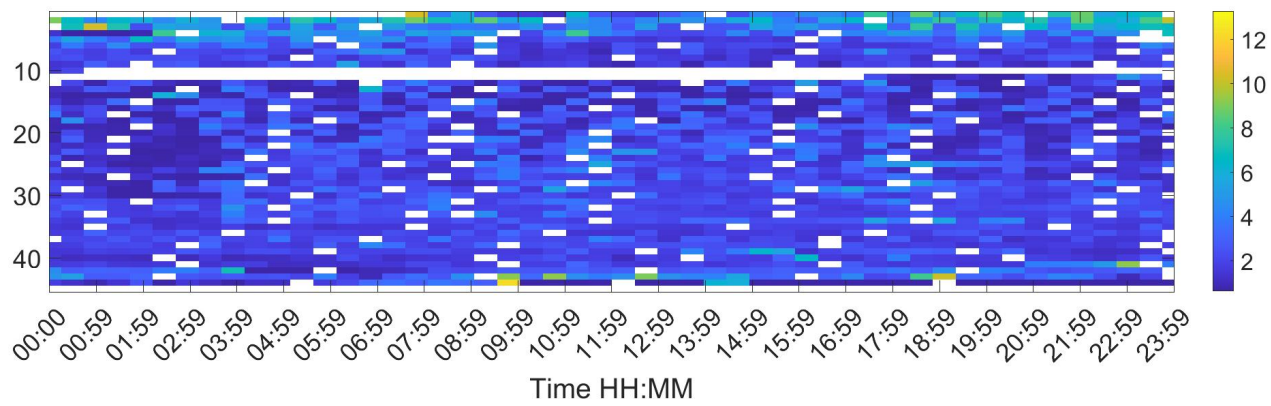

Figure 3. Map of the $L_{e q}$ variation for each day of the first campaign (C1). One value each $30 \mathrm{~min}$.

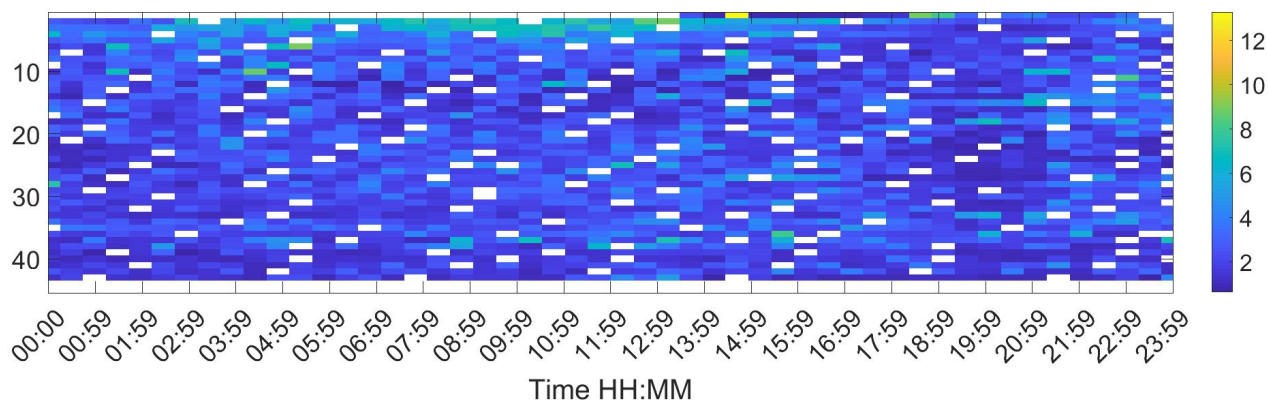

Figure 4. Map of the $L_{e q}$ variation for each day of the second campaign (C2). One value each $30 \mathrm{~min}$. 

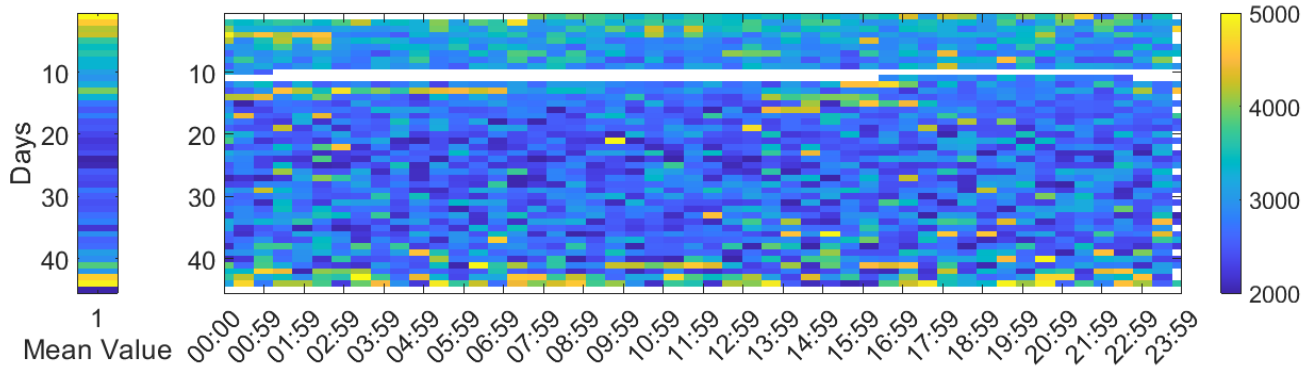

Time HH:MM

Figure 5. Map of the PF values for each day of the first campaign (C1). One value each 30 min.

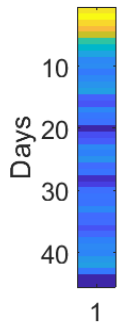

Mean Value

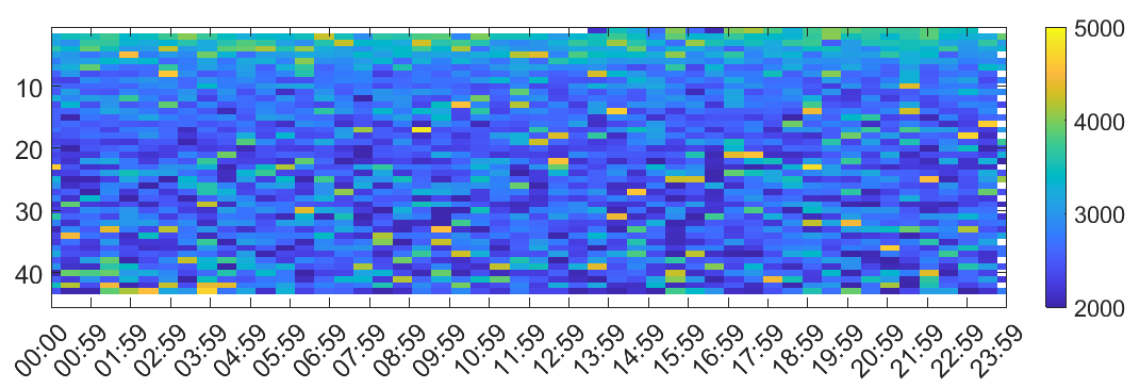

Time HH:MM

Figure 6. Map of the PF values for each day of the second campaign (C2). One value each $30 \mathrm{~min}$.

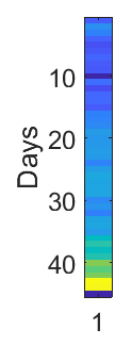

1
Mean Value

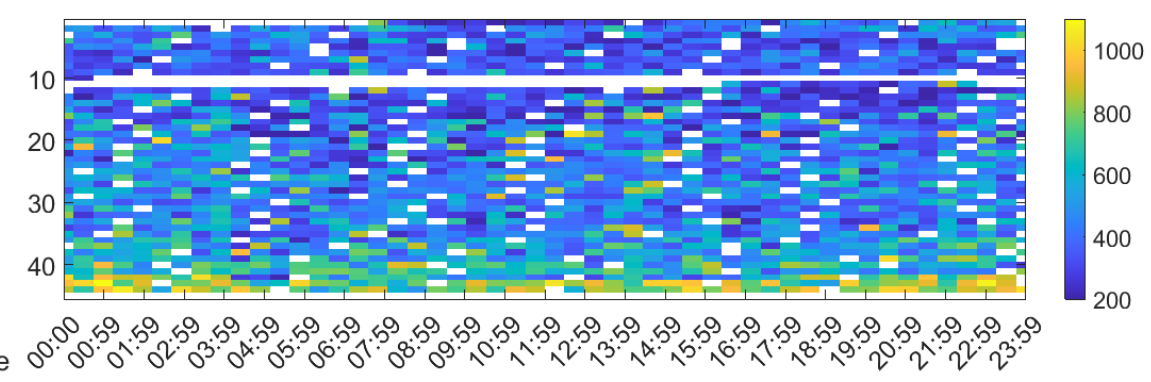

Time HH:MM

Figure 7. Map of the PF variation values for each day of the first campaign (C1). One value each $30 \mathrm{~min}$.

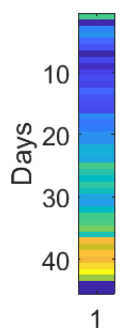

Mean Value

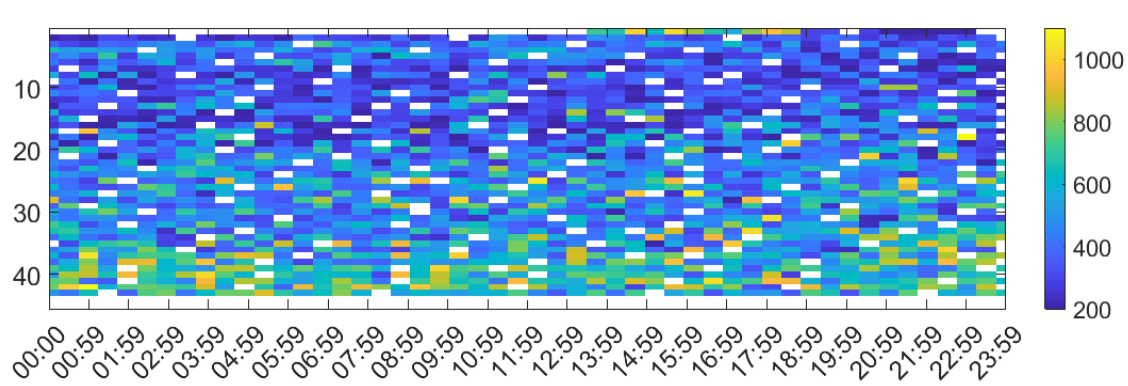

Time HH:MM

Figure 8. Map of the PF variation values for each day of the second campaign (C2). One value each $30 \mathrm{~min}$.

\section{Discussion}

The $L_{e q}$ captured at the arrival of the birds is the highest and long-lasting (around $5 \mathrm{~h}$ ) period of the analysis and has the same pattern in both campaigns. Meanwhile in winter there is an increase of the metrics during the daylight, the summer season do not show this pattern metric and more peaks 
are detected without any rule. Studying the variation of $\Delta L_{e q}$ it also has the highest and long-lasting variations during the first two days of birds' life. After the 20th day of life, we observe the same pattern between campaigns, a greater increase of $\Delta L_{e q}$ during daylight.

The PF captured the first fourth days of life indicates high values of frequency vocalisations in newborns. This days the birds' calls are due to their transport, stress and lack of familiar contact. The PF is in average lower during the winter campaign than in the summer. Also the $\mathrm{C} 2$ have more sporadic peaks of high frequencies than in winter. The $\triangle P F$ has the major increase the last three days of the production cycle where the birds are bigger in age and volume and more problems of coexistence can appear. There is also a pattern in the variation of $P F$ of both campaigns, where $\triangle P F$ increases in function of the age of the animal.

This preliminary comparison results encourage us to study deeply the relationship between the several parameters measured in [16], in order to detail the time-evolution of the several metrics that have shown relevant for the birds well-fare evaluation.

Author Contributions: G.J.G.-P. led the field work collecting the audio data, labelling, processing the dataset and participated in writing the entire paper. R.M.A.-P. has supported the signal processing part and participated in writing and reviewing of the entire paper. T.P.M. has supported the field work and reviewing the entire paper. All authors have read and agreed to the published version of the manuscript.

Funding: This research has been co-financed by Cealvet SLu and Ministry of Education. Gerardo Ginovart-Panisello would like to thank Administration of the Generalitat of Catalunya for the grant Collaboration scholarships for students in university departments for the academic year 2019-2020 (BOE núm. 156, 7 January 2019).

Acknowledgments: The authors would like to thank BonArea Agrupa carries out and controls all the feeding, breeding and feeding of the animals, the production of products, the logistics and direct sales up to the final consumer; all without any intermediary and with a complete and unique vertical integration model in the world. Also would like to thanks Vicenç Reñé Siuraneta for his knowledge and allowing us to study his commercial chicken farm, and for all the help during the process.

Conflicts of Interest: The authors declare no conflict of interest.

\section{Abbreviations}

The following abbreviations are used in this manuscript:

$L_{e q} \quad$ Equivalent pressure level

C1 Campaign One

C2 Campaign Two

PF Peak Frequency

\section{References}

1. Mead, G. Poultry Meat Processing and Quality; Elsevier: Amsterdam, The Netherlands, 2004.

2. Earth's dominant bird: A look at 100 years of chicken production.

3. Meluzzi, A.; Sirri, F. Welfare of broiler chickens. Ital. J. Anim. Sci. 2009, 8, 161-173.

4. Panisello, M. La patología y el medio ambiente en las granjas de broilers. In Proceedings of the Jornadas Profesionales de Avicultura de Carne, Real Escuela de Avicultura, Valladolid, Spain, 25-27 April 2005; Volume 2, p. 15-1.

5. World Animal Protection. Farm Animal Welfare; World Animal Protection: London, UK.

6. Tefera, M. Acoustic signals in domestic chicken (Gallus gallus): A tool for teaching veterinary ethology and implication for language learning. Ethiop. Vet. J. 2012, 16, 77-84.

7. Zuberbühler, K. Chapter 8 Survivor Signals: The Biology and Psychology of Animal Alarm Calling. In Advances in the Study of Behavior; Academic Press: Cambridge, MA, USA, 2009; Volume 40, pp. 277-322, doi:10.1016/S0065-3454(09)40008-1.

8. Clay, Z.; Smith, C.L.; Blumstein, D.T. Food-associated vocalizations in mammals and birds: What do these calls really mean? Anim. Behav. 2012, 83, 323-330, doi:10.1016/j.anbehav.2011.12.008. 
9. Delgado, R. Sexual Selection in the Loud Calls of Male Primates: Signal Content and Function. Int. J. Primatol. 2006, 27, 5-25, doi:10.1007/s10764-005-9001-4.

10. Herborn, K.A.; McElligott, A.G.; Mitchell, M.A.; Sandilands, V.; Bradshaw, B.; Asher, L. Spectral entropy of early-life distress calls as an iceberg indicator of chicken welfare. J. R. Soc. Interface 2020, 17, 20200086.

11. Blahová, J.; Dobšíková, R.; Straková, E.; Suchỳ, P. Effect of low environmental temperature on performance and blood system in broiler chickens (Gallus domesticus). Acta Vet. Brno 2007, 76, 17-23.

12. Appleby, M.C.; Hughes, B.O.; Elson, H.A. Poultry Production Systems. Behaviour, Management and Welfare; CAB International: Wallingford, UK, 1992.

13. Skomorucha, I.; Muchacka, R.; Sosnówka-Czajka, E.; Herbut, E. Response of broiler chickens from three genetic groups to different stocking densities. Ann. Anim. Sci. 2009, 9, 175-184.

14. Zoom Corporation. H5 Handy Recorder-Operation Manual; Zoom Corporation: Tokyo, Japan, 2014.

15. Behringer. Ultravoice XM1800S Technical Specifications; Behringer: Willich, Germany, 2011.

16. Ginovart-Panisello, G.J.; Alsina-Pagès, R.M.; Sanz, I.I.; Monjo, T.P.; Prat, M.C. Acoustic Description of the Soundscape of a Real-Life Intensive Farm and Its Impact on Animal Welfare: A Preliminary Analysis of Farm Sounds and Bird Vocalisations. Sensors 2020, 20, 4732.

Publisher's Note: MDPI stays neutral with regard to jurisdictional claims in published maps and institutional affiliations.

(C) 2020 by the authors. Licensee MDPI, Basel, Switzerland. This article is an open access article distributed under the terms and conditions of the Creative Commons Attribution (CC BY) license (http:// creativecommons.org/licenses/by/4.0/). 